\title{
Factors affecting mammalian carnivore use of riparian ecosystems in Mediterranean climates
}

\author{
Maria J. Santos,* Hugo M. Matos, Francisco Palomares, and Margarida Santos-Reis \\ Universidade de Lisboa, Faculdade de Ciências, Centro de Biologia Ambiental/Departamento de Biologia Animal, \\ Campo Grande, Bloco C2-5u Piso, 1749-016 Lisboa, Portugal (MJS, HMM, MS-R) \\ Department of Land, Air and Water Resources, University of California Davis, One Shields Avenue, Davis, CA 95616, \\ USA (MJS) \\ Departamento de Biología Aplicada, Estación Biológica de Doñana, Avenida de Maria Luisa s/n, Pabellón del Perú, \\ E-41013 Sevilla, Spain (FP) \\ * Correspondent: mjsantos@ucdavis.edu
}

\begin{abstract}
Riparian ecosystems serve as movement and dispersal corridors; however, the factors that determine their use by multiple species of carnivores remain unknown. Two hypotheses can explain carnivore presence in riparian ecosystems. Higher riparian plant richness, diversity, and structure provide the resources used by carnivores (resting sites, cover, and food). Alternatively, areas with higher water availability allow species to withstand water loss and thermal gradients in the high summer temperatures. In southern Portugal we surveyed 70 transects $2 \mathrm{~km}$ long along riparian ecosystems during the wet winter months and again in the dry summer months, recording signs of carnivore species and the environmental context in which they occurred (vegetation descriptors, surrounding landscape, and waterway type and condition). Five carnivore species used riparian ecosystems (stone marten [Martes foina], Eurasian badger [Meles meles], common genet [Genetta genetta], Egyptian mongoose [Herpestes ichneumon], and red fox [Vulpes vulpes]). Riparian ecosystems had a diverse and heterogeneous plant community with a mix of obligate riparian, Mediterranean sclerophyllous, and exotic species. Most carnivore species responded to water channel type and standing water availability in both seasons, except for the stone marten in the wet season, which uses areas with rich riparian vegetation. Our results suggest that the use of riparian ecosystems is linked to water availability that provides water, prey, and external temperature regulation.
\end{abstract}

Key words: Carnivora, food resources, habitat use, mammals, movement, water

Mammalian carnivores that occupy large home ranges and often disperse long distances (Sunquist and Sunquist 2001) are particularly susceptible, both directly and indirectly, to the structure and dynamics of their habitat (Hargis et al. 1999; Schonewald-Cox et al. 1998). In the Mediterranean, to respond to the inherent patchiness of the landscape (Blondel 2006, 2008) and seasonally variable resources (Loureiro et al. 2009; Rosalino et al. 2005a), most carnivore species use multiple habitat components, which often include riparian ecosystems (Maiorano et al. 2006; Pereira and Rodriguez 2010; Rosalino et al. 2005b; Santos and Beier 2008; Santos-Reis et al. 2004; Virgós 2001b). The landscape structure of riparian ecosystems (linear and narrow strips of vegetation along waterways) makes them difficult to detect and map consistently as a separate ecosystem, likely misrepresenting the role of the riparian ecosystem in supporting carnivore populations.
Riparian ecosystems have high and frequently unique biodiversity (Sabo et al. 2005), given their small land area. They also serve multiple roles, including water provision, nutrient retention (Jacobs et al. 2007), refuge for unique species (Sabo et al. 2005), and as movement and dispersal corridors (Beier and Noss 1998; Burbrink et al. 1998; Machtans et al. 1996); however, riparian ecosystems can act as ecological traps (Ries and Fagan 2003). Despite the perceived importance of riparian ecosystems in carnivore population dynamics (Beier and Noss 1998; Falcy and Estades 2007; Hadadd et al. 2003; Hilty et al. 2006; Perault and Lomolino 2000; Pereboom et al. 2008; Singleton et al. 2002), very few studies have focused on the riparian ecosystem alone.

w w w. m a m m a lo g y. or g 

Some authors have described the role of riparian ecosystems as corridors for carnivores moving or dispersing between habitat patches (Dickson et al. 2005; Hilty et al. 2006; Hilty and Merenlender 2004), and others have discussed their role as resource provider (Matos et al. 2008; Virgós 2001a). Alternatively, both functions can operate simultaneously, providing both a linear landscape structure and necessary resources. In Mediterranean ecosystems riparian habitats potentially provide multiple resources. In this region carnivores have a much higher rate of fruit consumption than elsewhere in their distribution (Rosalino and Santos-Reis 2008) and can use trees as resting sites (Santos-Reis et al. 2004). Additionally, riparian ecosystems are likely key sources of water (Malanson 1993; Naiman and Décamps 1997), but this role has been greatly overlooked in riparian ecosystem use by carnivores (Hilty and Merenlender 2004; Matos et al. 2008; Virgós 2001a). Further, because different carnivore species perceive the landscape differently (Swihart et al. 2001), speciesspecific responses to the resources provided by riparian ecosystems can exist. Therefore it is important to understand the influence of each of these components and the mechanisms through which carnivores use riparian ecosystems.

We aimed at testing the consistency of use by mammalian carnivore species of riparian ecosystems in southern Portugal, and which resources might be driving this use. Two hypotheses can be advanced: higher riparian plant richness and diversity will provide the structure (e.g., cover, resting sites, and food) that promotes carnivore presence in riparian ecosystems; and, alternatively, the use of riparian ecosystems is linked to water availability that allows carnivores to withstand high summer temperatures. Our specific goals were to assess which characteristics of riparian ecosystems (plant species richness, diversity, composition and structure, water channel characteristics, and surrounding land use) influence habitat use, and to test if the use of riparian ecosystem characteristics is consistent across the seasons.

\section{Materials and Methods}

Study area.- The study area was a $6,400-\mathrm{km}^{2}$ square (80 3 $80 \mathrm{~km}$ ) located in the Alentejo region of southern Portugal (38u199N, 8u129W; Fig. 1). Topography ranges from coastal areas (sea level) to low-elevation mountains ( $400 \mathrm{~m}$ ). Temperature ranges between $28 \mathrm{uC}$ and $45.2 \mathrm{uC}$ according to the Portuguese Meteorology Institute (http://www.meteo.pt/). Precipitation averages $500 \mathrm{~mm} /$ year, with a dry period from June to September. This area is characterized by a heterogeneous landscape with $43 \%$ of extensive nonirrigated agriculture (hay, wheat, forage, etc.). The 2nd most important land cover type is the oak woodland (38\%) of cork (Quercus suber) and holm (Q. rotundifolia) oaks. Intensive irrigated agriculture is the least represented. The cork and holm oak woodlands, called montado, form the major remaining agro-silvo-pastoral system in Europe (Diáz et al. 1997; Scarascia-Mugnozza et al. 2000). Human settlements are sparse with activities generally restricted to summer cork extraction, livestock production (cattle, sheep, and goats), hunting (mainly wild rabbit [Oryctolagus cuniculus] and red-legged partridge [Alectoris rufa]), and traditional agriculture (including olive groves and vineyards). These landscapes have a prolific network of river channels and their tributaries, with associated riparian vegetation, that is often well developed and composed primarily of white poplar (Populus alba), raywood ash (Fraxinus angustifolia), gray willow (Salix atrocinerea), African tamarisk (Tamarix africana), oleander (Nerium oleander), and alder (Alnus glutinosa-Chícharo et al. 2001; Santos 2010). Terrestrial shrubs are dominated by rockrose (Cistus spp.) and blackberries (Rubus ulmifolius_-Aguiar and Ferreira 2005; Aguiar et al. 2001, 2006; Santos 2010).

Sampling design.-To assess the presence of carnivores in riparian ecosystems, 72 sampling transects $2 \mathrm{~km}$ long were selected from 40 quadrats using a stratified random procedure (Fig. 1). These sampling locations were stratified by watercourse type (creek, stream, and river), and by surrounding landscape matrix (cork oak woodland, holm oak woodland, and irrigated and nonirrigated agriculture). Two sites were excluded a posteriori due to a lack of access. Transects were subdivided into 200-m segments to quantify carnivore presence, presence of riparian woody plant species, and environmental parameters.

Carnivore data collection.-We conducted sign surveys by walking transects in the effective 70 sampling sites (Fig. 1). At each sampling location the transect was walked within $5 \mathrm{~m}$ of the watercourse bank at an average speed of $2.02 \mathrm{~km} / \mathrm{h}$. Transects were visited twice, 1st between December 2003 and March 2004 (wet season) and repeated between June and September 2004 (dry season). The target carnivore species were red fox (Vulpes vulpes), least weasel (Mustela nivalis), European polecat (Mustela putorius), stone marten (Martes foina), Eurasian badger (Meles meles), common genet (Genetta genetta), Egyptian mongoose (Herpestes ichneumon), Iberian lynx (Lynx pardinus), and wildcat (Felis silvestris). The European otter (Lutra lutra) was excluded because it is a riparian-obligate carnivore. Because no signs of weasel, polecat, Iberian lynx, and wildcat were found, these species were not considered for further analysis. All signs of carnivore presence (tracks, scats, latrines, and animal carcasses) were recorded as number of signs for each 200-m segment of transect. Latrines were counted as 1 sign of presence to avoid overestimation; tracks also were counted as 1 sign of presence and counted as a new sign only when a clear distinction between 2 tracks was found ( $-200 \mathrm{~m}$ apart). We then calculated the total number of signs for each transect and per season.

Sign surveys have been used widely to understand carnivore patterns of distribution, habitat use, behavioral traits, food habits, and parasite infestation (Smith et al. 2003). This method has the potential to provide information on ecological and population parameters and also is one of the most costeffective techniques to be applied in short-term monitoring protocols (Barea-Azcón et al. 2007). Several studies have addressed the benefits and drawbacks of noninvasive methods for detection of carnivores (Barea-Azcón et al. 2007; Long et al. 2008). Sign surveys have been used to detect most 


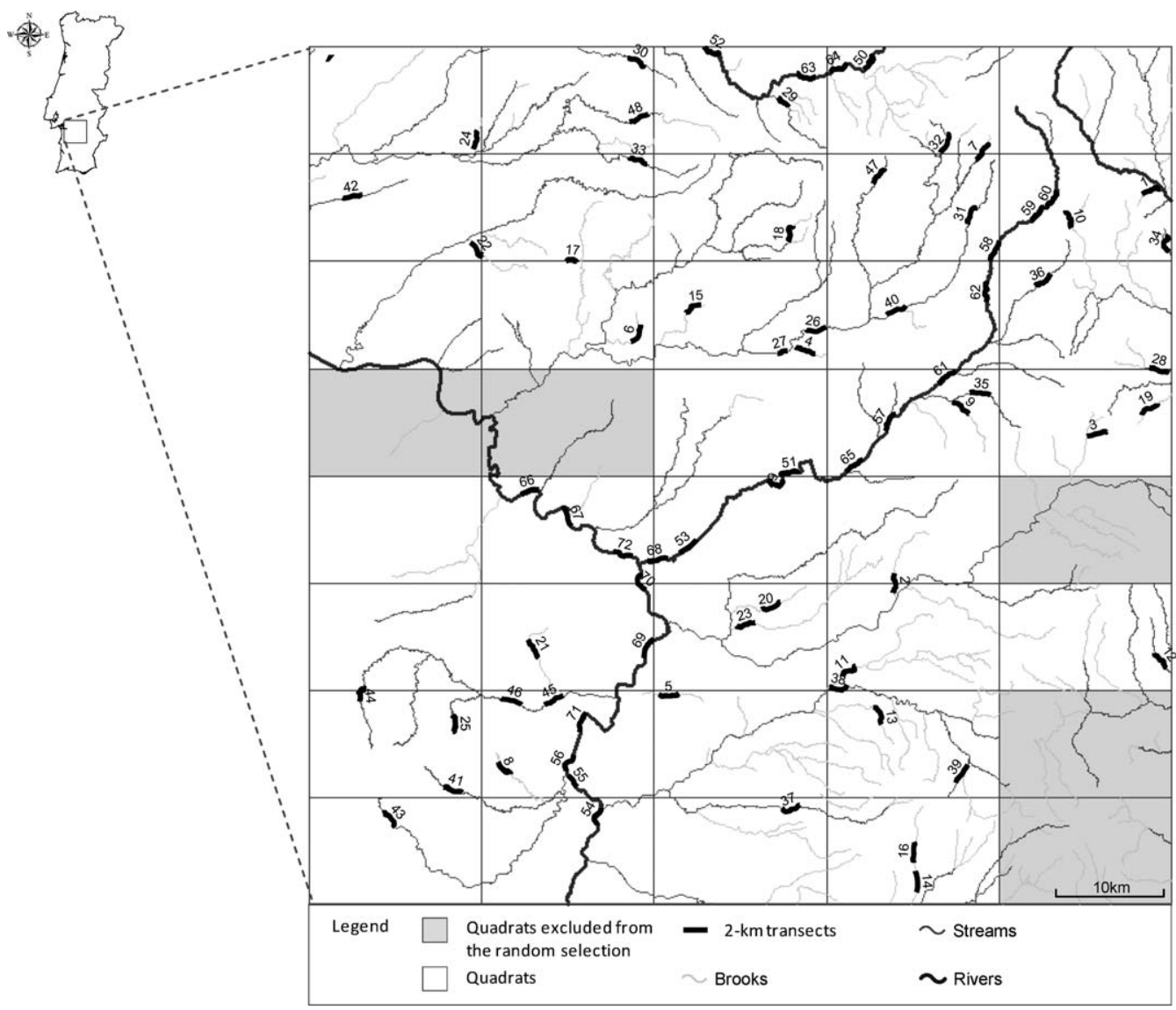

FIG. 1.-Study area location and geographical location of the 72 stratified randomly selected 2-km transects in the study area (southern Portugal). Transects 50 and 52 were not sampled due to lack of accessibility.

carnivore groups, and multiple methods have been suggested, specifically detection of tracks, scats, scratches, and burrows, and the use of hair snares (Long et al. 2008; Sadlier et al. 2004). Counter arguments question the reliability of scat surveys (Davison et al. 2002; Foran et al. 1997), because of misleading species identification, need for training of the observers, variable sign persistence due to environmental conditions, and variable detectability. In our case we believe that species identification was not problematic because the coexisting species have very distinct signs, identifiable according to their shape, size, odor, and location (Beltrán et al. 1991; Lawrence and Brown 1967). Transects always were walked by the same 2 experienced observers, reducing the potential for observer error. However, a potential exists for variable sign persistence in the 2 sampled seasons, and we were not able to detect a change in use over seasons.

The probability of detection affects most wildlife studies, because it varies with environmental conditions, terrain, and habitat, all of which influence the ability of the observer to detect the animal. Detections under different conditions become more difficult to compare, hindering data acquisition and quality and inferences made from those data. To account for the effect of variable probabilities of detection several methods have been developed; however, they often require a sampling design that involves replicated surveys in time or space (MacKenzie et al. 2003a, 2003b). Unfortunately our sampling design for the current study does not allow estimating probability of detection from our own samples (tracks, scats, latrines, and animal carcasses), because the study does not include short-term temporal replication, and the properties of each sampled location do not ensure spatial replication. However, in a subsequent study that we conducted with the same species we estimated detection probabilities for each of these species using repeated scat surveys (in the current study scats correspond to $75 \%$ of the samples). Probabilities of detection were as follows: stone marten 5 0.57, Eurasian badger 5 0.16, Egyptian mongoose 5 0.26, common genet 5 0.02, and red fox 50.45 (M. Santos, pers. obs.). These results are comparable to detection probabilities of North American carnivores (Gompper et al. 2006).

Riparian plant richness and diversity.-Presence of woody plant species (trees and shrubs) along the 70 transects was recorded in each 200-m segment (Table 1). Herbs were not included because of the difficulty in identification of annual vegetation and because they are not key resources for carnivores (Schmitz et al. 2000); in addition, grazing and human activities decrease herbaceous vegetation density and increased identification problems. Plant richness was estimated as the sum of total identified species in each transect. Plant diversity was estimated using both Simpson and Shannon's indexes and Shannon equitability index (Krebs 1999). The Shannon diversity index (H9) emphasizes rare species, whereas 
TABLE 1.-Types of environmental parameters and their descriptions and units measured in 2-km transects along riparian ecosystems in southern Portugal. NA—not applicable; \%—percent; P/A—presence/absence.

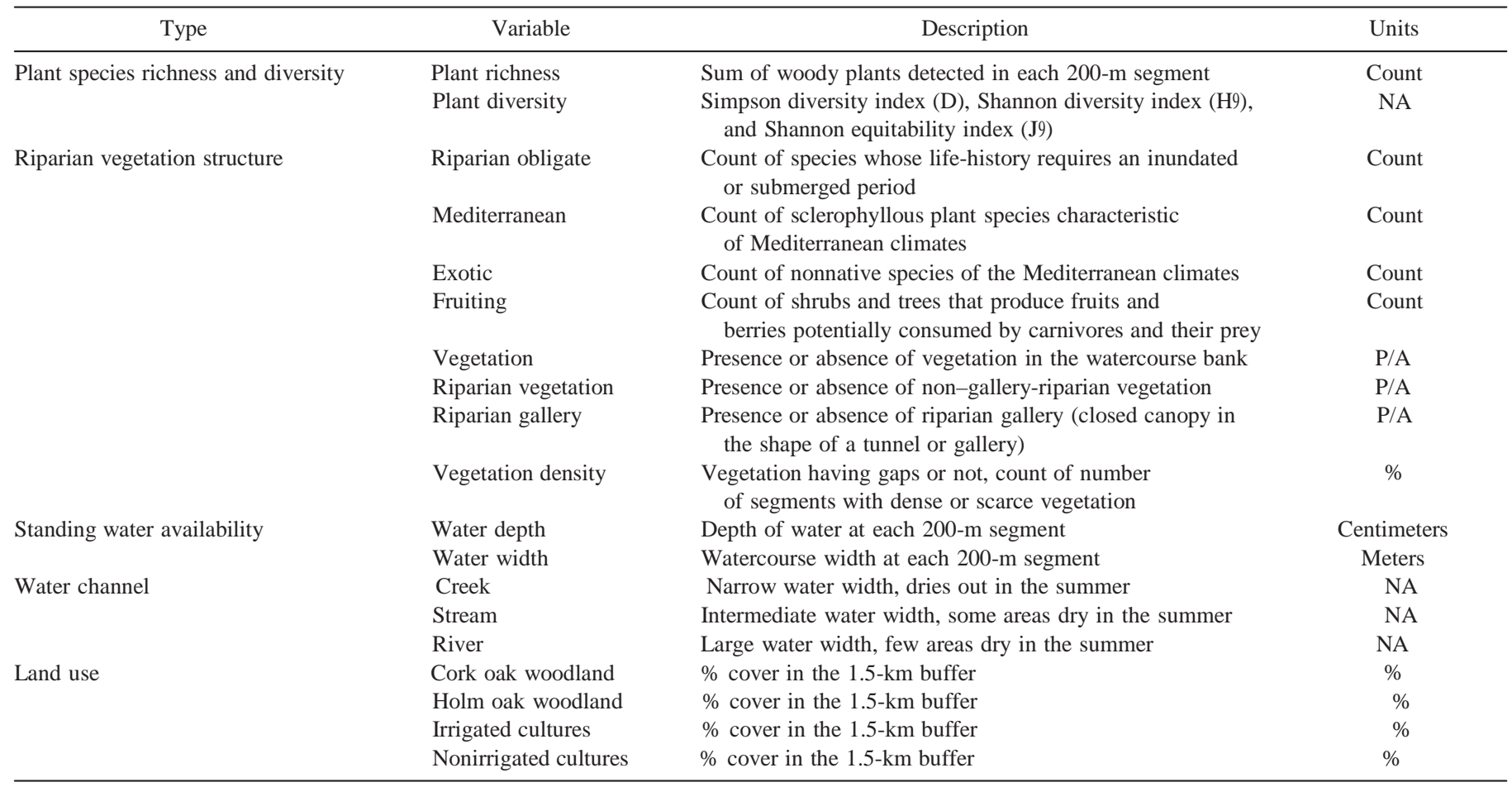

the Simpson diversity index (D) weights common species. H9 varies between 0 and $\log (\mathrm{k})$, where $\mathrm{k}$ is the number of classes, and D varies from 0 to ${ }^{+}{ }^{\star}$. Shannon's equitability index (J9) assumes values between 0 and 1 , with 1 being complete evenness in plant composition and corresponding to samples receiving the maximum value of $\mathrm{H} 9$.

Riparian ecosystem environmental context.-To characterize the environmental context of each riparian transect we recorded information on riparian vegetation structure, standing water availability, and land use (Table 1). Vegetation structure was determined by several variables, which described the plant species ecophysiological categories, vegetation structure, and density. We separated plant species into 4 ecophysiological categories: riparian obligate (whose life history requires an inundated or submerged period), Mediterranean (plants with sclerophyllous characteristics typical of Mediterranean climates), exotic (nonnative species), and fruiting species (fruit or berry producers known to be ingested by carnivores). To describe the structure of the vegetation along the riparian transect we determined whether vegetation was lacking, or if present if it was non-gallery-forming riparian vegetation or a riparian gallery forest (closed canopy in the shape of a tunnel). We also categorized vegetation density. Density was measured as scarce or dense, depending on whether either large gaps ( $-20 \mathrm{~m}$ ) between plants occurred along $-50 \%$ of the transect (scarce) or the vegetation constituted a continuous patch (dense). Standing water availability was established by measuring water depth $(\mathrm{cm})$ and water width $(\mathrm{m})$ at the beginning and end of each 200-m segment. Finally, land use surrounding the transect was categorized and quantified as percent cover for 5 classes (cork oak woodland, holm oak woodland, nonirrigated agriculture, irrigated agriculture, and other types; Table 1). Land-use data were obtained from available 2000 Coordination of Information on the Environment (CORINE) land-cover data (derived from classification of Landsat Thematic Mapper 30-m-resolution multispectral imagery; http://www.eea.europa.eu/themes/landuse/).

Statistical analyses.-To assess carnivore sample representativeness we plotted a cumulative curve of species signs within each transect (Ray and Sunquist 2001). If the curve reached an asymptote for a species it meant that that transect type was sufficient to represent that species. Because the curves for each type of transect (creek, stream, and river) reached an asymptote at 20, 22, and 20 of 24 transects, respectively, we assumed the sample size was sufficient to represent all species.

We tested if carnivore species presence in each season was a function of riparian plant richness and diversity, vegetation structure, standing water availability, and land use. We 1st tested if the variables within each of these categories and across these categories (Table 1) were correlated using Pearson's correlation coefficient (r) between pairs of variables. Pairs of variables with a correlation coefficient - 0.7 were screened, and the variable from the pair that had the highest correlation with the presence of carnivore species was included. High correlation was only observed between plant richness and diversity and between richness and strictly Mediterranean plants. We kept the richness and excluded the effect of diversity metrics and richness of strictly Mediterranean plants. For each species and season we created a suite of 
10 generalized linear models, using a logit link function to describe the binary nature of the dependent variable (presence/ absence of a carnivore species in a transect, estimated by summing all the segments within the transect). We tested the following suite of models: 1-plant richness, 2-plant structure, 3-water channel, 4-standing water availability, 5-land use, 6-plant richness + structure, 7-water channel + standing water availability, 8-plant richness + structure + water channel + standing water availability, 9-plant richness + structure + land use, and 10-plant richness + structure + water channel + standing water availability + land use. We then used Akaike's information criterion (AIC), its deviation from the top model (DAIC, where DAIC 50 for the top model), and its weights ( $\mathrm{w}_{\mathrm{i}} \mathrm{S}$ - Akaike 1981) to select the best models within the 10 generalized linear models. This information criterion approach allows selecting the most-parsimonious model, penalizing overfitted models that include too many parameters. Models with DAIC $>2$ are considered competitive and not distinguishable (Burnham and Anderson 1998). Variables were considered significant to the model when $\mathrm{P}>0.05$. After model selection, model performance was assessed in model ability to predict the dependent variable by calculating the area under the curve (AUC), derived from receiver-operating characteristics plots. This is a measure of the ability of the model to predict presences appropriate for binary data (Hanley and McNeil 1982) and is obtained by plotting sensitivity (the conditional probability that a positive case if correctly classified) versus 1 specificity (the conditional probability that a negative case is correctly classified). All tests were performed in JMP version 5 (SAS Institute, Inc., Cary, North Carolina).

\section{RESUlts}

Carnivore presence and plant richness and diversity.-We found a total of 1,479 signs of carnivores in the surveyed riparian ecosystems, with 849 signs found during the rainy season and 630 in the dry season. The maximum richness observed at any given transect was 5 carnivore species (stone marten, Eurasian badger, Egyptian mongoose, common genet, and red fox). The most detected species were the Egyptian mongoose (44.2\%), red fox $(21.1 \%)$, and badger (17.2\%), and the least detected species were the genet $(8.4 \%)$ and the stone marten (8.7\%).

Riparian plant richness was composed of a maximum of 52 plant species, from which 34 species are autochthonous of Mediterranean ecosystems. Along transects raywood ash (60.6\%), cork oak (40.7\%), willows (40.1\%), black poplar (Populus nigra; 33.1\%), olive tree (Olea europaea; 31\%), and holm oak (30.2\%) were the most common tree species, and blackberries (79.5\%) and rockroses (36.1\%) were the most common shrubs. Plant richness (average richness 5 14.7) and diversity (H9 5 2.99; D 5 17.19) were relatively high. Plants were distributed homogeneously across waterways (J9 5 0.76). Vegetation along riparian ecosystems formed galleries in $>50 \%$ of the sampled areas.

Environmental predictors of seasonal carnivore presence.Environmental factors explained a considerable amount of the observed variability in the presence of carnivore species. AIC, DAIC, and $\mathrm{w}_{\mathrm{i}}$ showed that the most-parsimonious models were species-specific (Table 2). Nonetheless, most of the selected models (higher $\mathrm{w}_{\mathrm{i}} \mathrm{s}$ ) included water channel and standing water availability in both seasons, with the exception of the stone marten in the wet season (Table 2). In the wet season the Eurasian badger, the Egyptian mongoose, and the genet were positively associated with smaller and deeper water courses, whereas the stone marten and the red fox were positively associated with larger and shallower water courses (Table 3). The stone marten is the only species showing a positive association with plant richness in the wet season. In the dry season the stone marten, Eurasian badger, and red fox maintain their associations with water courses, and the Egyptian mongoose and the common genet become positively associated with larger and deeper water courses (Table 3). Model performance was variable with species and season (stone marten: wet season $\mathrm{AUC}_{\text {model1 }} 50.80$ and $\mathrm{AUC}_{\text {model5 }} 5$ 0.72, and dry season $\mathrm{AUC}_{\text {model5 }} 5$ 0.82; Eurasian badger: wet season $\mathrm{AUC}_{\text {model7 }} 5$ 0.78, and dry season $\mathrm{AUC}_{\text {model7 }} 5$ 0.82; Egyptian mongoose: wet season $\mathrm{AUC}_{\text {model4 }} 5$ 0.84, and dry season $\mathrm{AUC}_{\text {model } 4} 50.67$ and $\mathrm{AUC}_{\text {model3 }} 5$ 0.65; common genet: wet season $\mathrm{AUC}_{\text {model7 }} 5$ 0.66, and dry season $\mathrm{AUC}_{\text {model7 }} 5$ 0.59, $\mathrm{AUC}_{\text {model } 4} 5$ 0.62, and $\mathrm{AUC}_{\text {model3 }} 5$ 0.62; red fox: wet season $\mathrm{AUC}_{\text {model3 }} 5$ 0.65, and dry season $\mathrm{AUC}_{\text {model4 }} 5$ 0.65).

\section{DisCUSSION}

Two competing hypotheses potentially can explain carnivore use of riparian ecosystems: higher riparian plant richness and diversity will provide the structure (resting sites, cover, and food) that promotes carnivore presence in riparian ecosystems; and, alternatively, the use of riparian ecosystems is linked to water availability that allows carnivores to withstand high summer temperatures. Our results strongly support the latter hypothesis rather than the 1st, because the presence of all species was mostly linked to water channel type and standing water availability in both seasons, with the exception of the stone marten in the wet season.

Our results suggest that available standing water is a key resource for carnivore species in Mediterranean environments. This is a striking finding, because most studies have shown the importance of riparian ecosystems as providers of food (Matos et al. 2008; Pereira and Rodriguez 2010), cover (Mangas et al. 2008; Pereira and Rodriguez 2010; Virgós 2001a), resting sites (Santos-Reis et al. 2004), and movement routes (Hilty and Merenlender 2004; Pereira and Rodriguez 2010), but none shows the potential role of standing water as a key resource. Potential explanations for the importance of standing water include availability of water, prey or food, and external temperature regulation.

Water ingestion by carnivores is not well documented, because measurements of water intake are difficult to achieve in the field. Water intake calculations require collection of frozen urine (Darnell et al. 2005), which was not possible in our study area. Nonetheless, water uptake can occur indirectly 
TABLE 2.-Akaike's information criterion (AIC), deviation from the top model (DAIC, where * indicates 2 competitive and not distinguishable models), and AIC weights ( $\mathrm{w}_{\mathrm{i}}$ ) for generalized linear models (GLMs) of carnivore presence related to environmental properties of riparian ecosystems. Bold values represent the most-parsimonious models (1-plant richness, 2-plant structure, 3-water channel, 4standing water availability, 5-land use, 6-plant richness + structure, 7-water channel + standing water availability, 8-plant richness + structure + water channel + standing water availability, 9-plant richness + structure + land use, and 10 -plant richness + structure + water channel + standing water availability + land use).

\begin{tabular}{|c|c|c|c|c|c|c|c|c|c|c|c|}
\hline & GLMs & 1 & 2 & 3 & 4 & 5 & 6 & 7 & 8 & 9 & 10 \\
\hline \multicolumn{12}{|c|}{ Stone marten } \\
\hline \multirow[t]{3}{*}{ Wet } & AIC & 38.60 & 50.84 & 44.76 & 45.04 & 39.39 & 44.84 & 43.95 & 43.86 & 46.15 & 43.21 \\
\hline & DAIC & $0.00^{*}$ & 12.24 & 6.16 & 6.44 & $0.79 *$ & 6.24 & 5.35 & 5.26 & 7.55 & 4.61 \\
\hline & $\mathrm{w}_{\mathrm{i}}$ & 0.48 & 0.00 & 0.02 & 0.02 & 0.33 & 0.02 & 0.03 & 0.03 & 0.01 & 0.05 \\
\hline \multirow[t]{3}{*}{ Dry } & AIC & 144.34 & 135.34 & 131.13 & 63.70 & 139.46 & 144.27 & 58.52 & 70.46 & 147.58 & 72.39 \\
\hline & DAIC & 85.82 & 76.82 & 72.61 & 5.18 & 80.94 & 85.75 & 0.00 & 11.94 & 89.06 & 13.87 \\
\hline & $\mathrm{w}_{\mathrm{i}}$ & 0.00 & 0.00 & 0.00 & 0.07 & 0.00 & 0.00 & 0.93 & 0.00 & 0.00 & 0.00 \\
\hline \multicolumn{12}{|c|}{ Eurasian badger } \\
\hline \multirow[t]{3}{*}{ Wet } & AIC & 214.11 & 206.93 & 216.54 & 191.58 & 219.64 & 211.02 & 181.13 & 188.15 & 217.35 & 192.43 \\
\hline & DAIC & 32.98 & 25.80 & 35.41 & 10.45 & 38.51 & 29.89 & 0.00 & 7.02 & 36.22 & 11.30 \\
\hline & $\mathrm{w}_{\mathrm{i}}$ & 0.00 & 0.00 & 0.00 & 0.01 & 0.00 & 0.00 & 0.96 & 0.03 & 0.00 & 0.00 \\
\hline \multirow[t]{3}{*}{ Dry } & AIC & 62.94 & 70.89 & 65.22 & 47.53 & 67.36 & 55.67 & 44.18 & 52.06 & 59.67 & 56.38 \\
\hline & DAIC & 18.76 & 26.71 & 21.04 & 3.35 & 23.18 & 11.49 & 0.00 & 7.88 & 15.49 & 12.20 \\
\hline & $\mathrm{w}_{\mathrm{i}}$ & 0.00 & 0.00 & 0.00 & 0.15 & 0.00 & 0.00 & 0.82 & 0.02 & 0.00 & 0.00 \\
\hline \multicolumn{12}{|c|}{ Egyptian mongoose } \\
\hline \multirow[t]{3}{*}{ Wet } & AIC & 273.99 & 274.31 & 271.73 & 267.52 & 275.35 & 281.09 & 288.77 & 275.91 & 285.89 & 280.33 \\
\hline & DAIC & 6.47 & 6.79 & 4.21 & 0.00 & 7.83 & 13.57 & 21.25 & 8.39 & 18.37 & 12.81 \\
\hline & $\mathrm{w}_{\mathrm{i}}$ & 0.03 & 0.03 & 0.10 & 0.81 & 0.02 & 0.00 & 0.00 & 0.01 & 0.00 & 0.00 \\
\hline \multirow[t]{3}{*}{ Dry } & AIC & 207.87 & 212.65 & 205.41 & 205.76 & 208.69 & 212.09 & 207.64 & 215.27 & 215.72 & 217.95 \\
\hline & DAIC & 2.46 & 7.24 & $0.00 *$ & $0.35^{*}$ & 3.28 & 6.68 & 2.23 & 9.86 & 10.31 & 12.54 \\
\hline & $\mathrm{w}_{\mathrm{i}}$ & 0.11 & 0.01 & 0.37 & 0.31 & 0.07 & 0.01 & 0.12 & 0.00 & 0.00 & 0.00 \\
\hline \multicolumn{12}{|c|}{ Common genet } \\
\hline \multirow[t]{3}{*}{ Wet } & AIC & 191.16 & 194.22 & 188.78 & 171.95 & 193.59 & 200.23 & 171.06 & 179.74 & 205.04 & 183.48 \\
\hline & DAIC & 20.10 & 23.16 & 17.72 & $0.89 *$ & 22.53 & 29.17 & $0.00 *$ & 8.68 & 33.98 & 12.42 \\
\hline & $\mathrm{W}_{\mathrm{i}}$ & 0.00 & 0.00 & 0.00 & 0.39 & 0.00 & 0.00 & 0.60 & 0.01 & 0.00 & 0.00 \\
\hline \multirow[t]{3}{*}{ Dry } & AIC & 55.89 & 55.93 & 49.69 & 49.75 & 53.03 & 64.14 & 50.31 & 64.39 & 68.88 & 68.55 \\
\hline & DAIC & 6.20 & 6.24 & $0.00^{*}$ & $0.06^{*}$ & 3.34 & 14.45 & $0.62 *$ & 14.70 & 19.19 & 18.86 \\
\hline & $\mathrm{w}_{\mathrm{i}}$ & 0.02 & 0.01 & 0.34 & 0.33 & 0.06 & 0.00 & 0.25 & 0.00 & 0.00 & 0.00 \\
\hline \multicolumn{12}{|c|}{ Red fox } \\
\hline \multirow[t]{3}{*}{ Wet } & AIC & 216.13 & 212.64 & 208.62 & 205.17 & 214.69 & 217.80 & 206.50 & 211.86 & 224.43 & 217.40 \\
\hline & DAIC & 10.96 & 7.47 & 3.45 & $0.00 *$ & 9.52 & 12.63 & $1.33 *$ & 6.69 & 19.26 & 12.23 \\
\hline & $\mathrm{w}_{\mathrm{i}}$ & 0.00 & 0.01 & 0.10 & 0.57 & 0.00 & 0.00 & 0.29 & 0.02 & 0.00 & 0.00 \\
\hline \multirow[t]{3}{*}{ Dry } & AIC & 113.85 & 116.54 & 104.03 & 110.68 & 105.11 & 119.99 & 107.63 & 118.35 & 114.69 & 116.46 \\
\hline & DAIC & 9.82 & 12.51 & 0.00 & 6.65 & 1.08 & 15.96 & 3.60 & 14.32 & 10.66 & 12.43 \\
\hline & $\mathrm{w}_{\mathrm{i}}$ & 0.00 & 0.00 & 0.56 & 0.02 & 0.32 & 0.00 & 0.09 & 0.00 & 0.00 & 0.00 \\
\hline
\end{tabular}

through the consumption of water-rich food resources, which can contain up to $70 \%$ water (Nagy et al. 1999). However, not all species are equally efficient in water uptake from prey. Felids, for example, are less sensitive to dehydration than are canids and other omnivores (Zoran 2002). Thus, future research should focus on understanding the role of water uptake, establish how much of the water requirements can be acquired through the ingestion of food resources, and how these can serve as surrogate measurements of water uptake.

Standing water also can provide food resources for carnivores. Larger and deeper bodies of water retain flowing water and are likely to support a higher diversity of food resources (Williams et al. 2003), including crayfish (Procambarus clarkii-Correia 2001). Crayfish becomes available to these species during the summer, when parts of waterways in Mediterranean climates dry out and form ponds. Crayfish has been recognized as an important food resource for the carnivore community in the Iberian Peninsula (Correia 2001; Tablado et al. 2010); however, being an invasive species, it creates a conservation challenge (Tablado et al. 2010). We also have observed crayfish—a food item that can be obtained only from standing water-in the diet of the stone marten, common genet, Egyptian mongoose (Santos et al. 2007), Eurasian badger, and red fox (Correia 2001; Santos et al. 2007). In addition, other key food items are more abundant in riparian ecosystems, such as berry-producing plants, arthropods, and small mammals (Santos et al. 2007), which are consumed by most of the species considered herein (Barrientos and Virgós 2006; Ciampalini and Lovari 1985; Loureiro et al. 2009; Mortelliti and Boitani 2008; Rosalino et al. 2005a; Rosalino and Santos-Reis 2002, 2008; Santos et al. 2007). Therefore, a potential indirect effect of standing water is the 
TABLE 3.- Variable signs for wet and dry seasons for the mostparsimonious models selected using Akaike's information criterion weights of generalized linear models of carnivore presence related to environmental properties of riparian ecosystems.

\begin{tabular}{lccccc}
\hline & \multicolumn{5}{c}{ Wet/dry season } \\
\cline { 2 - 6 } & Creek & Stream & River & Depth & Width \\
\hline Stone marten & $2 / 2$ & $+/ 2$ & $+/+$ & $2 / 2$ & $+/+$ \\
Eurasian badger & $+/+$ & $+/+$ & $2 / 2$ & $+/ 2$ & $+/+$ \\
Egyptian mongoose & $+/ 2$ & $+/ 2$ & $2 /+$ & $+/+$ & $2 / 2$ \\
Common genet & $+/+$ & $+/+$ & $2 /+$ & $+/+$ & $+/ 2$ \\
Red fox & $2 /+$ & $+/ 2$ & $+/ 2$ & $2 / 2$ & $+/+$ \\
\hline
\end{tabular}

increase in the persistence of plants along water courses (Malanson 1993; Naiman and Décamps 1997), and thus of associated food resources. However, our results did not show an importance of riparian plants or just fruit-producing plants in carnivore presence. Two potential confounding factors can be occurring, a mismatch between the seasonality of fruits and that of our sampling, and a diluted effect by using metrics such as species richness rather than the identity of the species themselves. We know that carnivores in Mediterranean ecosystems track the seasonal availability of food resources (Barrientos and Virgós 2006; Loureiro et al. 2009; Rosalino et al. 2005a) and that fruits are key resources (Herrera 1989, 1995; Rosalino and Santos-Reis 2008). Because fruiting is highly variable from year to year, we could have missed the key fruiting seasons or sampled just a few of them. The other confounding factor is the use of richness metrics rather than species identity. We believe that this might not be a problem, especially if the fruiting was missed during our sampling, and thus even if we had included the specific species, this likely would not reveal its importance.

Another factor to consider is the thermal regulation that occurs in riparian ecosystems. Evaporation of standing water allows for thermal exchanges with the atmosphere, resulting in an overall decrease in external temperature. This phenomenon has been evoked to explain exclusion of the common genet from very cold mountain riparian ecosystems in Spain (Virgós 2001a) but not in other areas (Pereira and Rodriguez 2010). Temperatures of riparian ecosystems of southern Portugal are not as low as in northern Spain, and genets might tolerate them even during the winter. We believe the most challenging temperatures in southern Europe are the high summer temperatures (30-40uC), which probably can be reduced by the effect of a standing body of water on overall ambient temperature. This is particularly important for species such as the Egyptian mongoose, which is diurnal (Palomares and Delibes 1992) and avoids open areas (Palomares and Delibes 1993). The same explanation has been suggested for the selection of resting sites in riparian ecosystems by nocturnal species, such as the stone marten (Santos-Reis et al. 2004; M. Santos-Reis, pers. obs.), the common genet (Espírito-Santo et al. 2007; Pereira and Rodriguez 2010; Santos-Reis et al. 2004), and the Eurasian badger (Mangas et al. 2008; Rosalino et al. 2005b; Virgós 2001a, 2001b).
It is important to differentiate between water availability (depth and width of water course) and the use of different water courses (creeks, streams, and rivers), which were the variables consistently related to carnivore presence in the riparian ecosystem. Different types of water course likely indicate how different the riparian ecosystem is from the surrounding landscape. Creeks are narrower and shallower, and the riparian ecosystem width is reduced and composed of plant species more similar to those in the surrounding landscapes (Santos 2010). As water width and depth increases in streams and rivers, it is followed by an increase in riparian ecosystem width and obligate riparian plant species (Santos 2010). Our results show a consistent positive selection of larger water courses by the stone marten and of smaller water courses by the Eurasian badger and the common genet. The stone marten is the most arboreal species, so it selects riparian ecosystems more distinct from the surrounding landscape and likely having more trees and cover. This is probably why this is the only species that shows a positive association with plant richness in the wet season. In contrast, the Eurasian badger and common genet might require more constant cover and thus select riparian ecosystems that are less distinct from the surrounding landscape. Finally, the Egyptian mongoose and the red fox seem to be using riparian ecosystems independently of their similarity or distinction from the surrounding landscapes. Further studies, however, are required to elucidate this potential indirect effect of riparian ecosystem structure on mesocarnivore presence in these habitats, because the riparian structure variables that we measured were not statistically significant in our analysis.

Of the 9 species potentially using riparian ecosystems (red fox, weasel, polecat, stone marten, Eurasian badger, common genet, Egyptian mongoose, Iberian lynx, and wildcat), we were able to detect only 5 . Three of the undetected species are of conservation concern (polecat-Data deficient, Iberian lynx-Endangered, and wildcat-Data deficient) and thus rarer and more difficult to detect. The polecat is the only species with riparian ecosystem affiliation, and this species has been found elsewhere in southern Portugal (Santos et al. 2008). The Iberian lynx and the wildcat also were detected elsewhere in southern Portugal (Santos et al. 2008), but their habitat requirements are more linked with scrub and dense forest habitats, thus decreasing the likelihood of them being detected in riparian ecosystems (Castro and Palma 1996; Pires and Fernandes 2003; Sarmento 1996). The weasel also has habitat preferences for rocky areas (Santos-Reis 1989), which were not found in our study sites. The otter was detected in all of the surveyed transects, but we excluded it from the analysis, because it is a riparian-obligate carnivore.

Our analysis did not make comparisons that rely on knowing species detection probability, because we did no seasonal or species comparisons. Thus, we believe that our results would not be affected by the potential difference in the probability of detection of each species.

Our study emphasizes the relationship between carnivores and riparian ecosystems, especially standing water availability. The importance of standing water can be generalized across carnivore species, indicating the importance of water as a 
resource, for availability of prey or food, and for external temperature regulation. Faced with the current irreversible changes in Mediterranean riparian ecosystems (Salinas et al. 2000; Santos et al. 2002), we suggest proactive water management strategies such as water-use policies and regulations, pollution control, controlled water diversion, and the establishment of best management practices for water use, especially in the summer months. Implementing these actions likely will lead to the preservation of the riparian ecosystem and the resources that carnivore species depend upon.

\section{AcKnOwledgments}

This paper was funded by the Fundação para Ciência e Tecnologia project, Riparian Galleries as Corridors and Linkage Habitats in the Fragmented Landscape of Southern Portugal: Applications to Conservation Planning (POCTI/MGS/47435/2002; MJS: POCTI/MGS/ 47435/2002; HMM: SFRH/BD/10599/2002). We are grateful to A. R. Alves and L. M. Rosalino for their help during fieldwork. We thank M. Holyoak for insightful suggestions and edits to the manuscript. We also thank the associate editor, S. Wisely, for improvements to the manuscript. All experiments described herein comply with the Animal Welfare regulations by which research in Portugal is regulated.

\section{Literature Cited}

Aguiar, F. C., and M. T. Ferreira. 2005. Human-disturbed landscapes: effects on composition and integrity of riparian woody vegetation in the Tagus River basin, Portugal. Environmental Conservation 32:30-41.

Aguiar, F. C., M. T. Ferreira, and A. Albuquerque. 2006. Patterns of exotic and native plant species richness and cover along a semiarid Iberian river and across its floodplain. Plant Ecology 184: 189-202.

Aguiar, F. C., M. T. Ferreira, and I. Moreira. 2001. Exotic and native vegetation establishment following channelization of a western Iberian river. Regulated Rivers, Research and Management 17:509-526.

Akaike, H. 1981. Likelihood of a model and information criteria. Journal of Econometrics 16:3-14.

Barea-Azcó n, J. M., E. Virgós, E. Ballesteros-Duperon, M. Moleon, AND M. Chirosa. 2007. Surveying carnivores at large spatial scales: a comparison of four broad-applied methods. Biodiversity and Conservation 16:1213-1230.

Barrientos, R., and E. Virgós. 2006. Reduction of potential food interference in two sympatric carnivores by sequential use of shared resources. Acta Oecologica 30:107-116.

Beier, P., ANd R. Noss. 1998. Do habitat corridors provide connectivity? Conservation Biology 12:1241-1252.

Beltrán, J. F., M. Delibes, and J. R. Rau. 1991. Methods of censusing red fox (Vulpes vulpes) populations. Hystrix 3:199-214.

Blondel, J. 2006. The 'design' of Mediterranean landscapes: a millennial story of humans and ecological systems during the historic period. Human Ecology 34:713-729.

Blondel, J. 2008. On humans and wildlife in Mediterranean islands. Journal of Biogeography 35:509-518.

Burbrink, F. T., C. A. Phillips, and E. J. Heske. 1998. A riparian zone in southern Illinois as a potential dispersal corridor for reptiles and amphibians. Biological Conservation 86:107-115.

Burnham, K. P., And D. R. Anderson. 1998. Model selection and inference. Springer-Verlag. New York.
Castro, L. R., and L. Palma. 1996. The current status, distribution and conservation of Iberian lynx in Portugal. Journal of Wildlife Research 2:179-181.

Chícharo, M. A., et Al. 2001. Status of the Guadiana Estuary (south Portugal) during 1996-1998: an ecohydrological approach. Aquatic Ecosystem Health \& Management 4:73-89.

Ciampalini, B., and S. Lovari. 1985. Food habits and trophic niche overlap of the badger (Meles meles L.) and the red fox (Vulpes vulpes L.) in a Mediterranean coastal area. Zeitschrift für Säugetierkunde 50:226-234.

Correia, A. M. 2001. Seasonal and interspecific evaluation of predation by mammals and birds on the introduced red swamp crayfish Procambarus clarkii (Crustacea, Cambaridae) in a freshwater marsh (Portugal). Journal of Zoology (London) 255:533-541.

Darnell, A. E., K. E. Hodges, and C. G. Guglielmo. 2005. Urine urea-creatinine ratio of mammalian carnivores: a good nutritional index for the wrong reason? Wildlife Society Bulletin 33:13921397.

Davison, A., J. D. S. Birks, R. C. Brookes, T. C. Braithwaite, and J. E. Messenger. 2002. On the origin of faeces: morphological versus molecular methods for surveying rare carnivores from their scats. Journal of Zoology (London) 257:141-143.

Dí́z, M., P. Campos, And J. Pulido. 1997. The Spanish dehesas: a diversity in land-use and wildlife. Pp. 178-209 in Farming and birds in Europe: the common agriculture policy and its implications for bird conservation (D. J. Pain and M. W. Pierkowski, eds.). Academic Press, London, United Kingdom.

Dickson, B. G., J. S. Jenness, and P. Beier. 2005. Influence of vegetation, topography, and roads on cougar movement in southern California. Journal of Wildlife Management 69:264-276.

Espírito-Santo, C., L. M. Rosalino, and M. Santos-Reis. 2007. Factors affecting the placement of common genet latrine sites in a Mediterranean landscape in Portugal. Journal of Mammalogy 88:201-207.

Falcy, M. R., and C. F. Estades. 2007. Effectiveness of corridors relative to enlargement of habitat patches. Conservation Biology 21:1341-1346.

Foran, D. R., K. R. Crooks, and S. C. Minta. 1997. Species identification from scat: an unambiguous genetic method. Wildlife Society Bulletin 25:835-839.

Gompper, M. E., R. W. Kays, J. C. Ray, S. D. Lapoint, D. A. Bogan, AND J. R. CRYAn. 2006. A comparison of noninvasive techniques to survey carnivore communities in northeastern North America. Wildlife Society Bulletin 34:1142-1151.

Haddad, N. M., et Al. 2003. Corridor use by diverse taxa. Ecology 84:609-615.

Hanley, J. A., And B. J. McNeIL. 1982. The meaning and use of the area under a receiver operating characteristic (ROC) curve. Radiology 143:29-36.

Hargis, C. D., J. A. Bissonette, and D. L. Turner. 1999. The influence of forest fragmentation and landscape pattern on American martens. Journal of Applied Ecology 36:157-172.

Herrera, C. M. 1989. Frugivory and seed dispersal by carnivorous mammals, and associated fruit characteristics, in undisturbed Mediterranean habitats. Oikos 55:250-262.

Herrera, C. M. 1995. Dispersal systems in the Mediterranean: ecological, evolutionary and historical determinants. Annual Review of Ecology and Systematics 26:705-727.

Hilty, J. A., W. Z. Lidicker, and A. M. Merelender. 2006. Corridor ecology - the science and practice of linking landscapes for biodiversity conservation. Island Press, Washington, D.C. 
Hilty, J. A., And A. M. Merenlender. 2004. Use of riparian corridors and vineyards by mammalian predators in Northern California. Conservation Biology 18:126-135.

JACOBS, S. M., ET AL. 2007. Nutrient vectors and riparian processing: a review with special reference to African semiarid savanna ecosystems. Ecosystems 10:1231-1249.

KreBs, C. J. 1999. Ecological methodology. 2nd ed. Addison-Wesley Educational Publishers, Inc., Menlo Park, California.

Lawrence, M. J., and R. W. Brown. 1967. Mammals of Britain, their tracks, trails and signs. Blandford, London, United Kingdom.

Long, R. A., P. MacKay, W. J. Zielinski, And J. C. Ray. 2008. Noninvasive survey methods for carnivores. Island Press, Washington, D.C.

Loureiro, F., J. A. Bissonette, D. W. MacDonald, and M. SantosReIs. 2009. Temporal variation in the availability of Mediterranean food resources: do badgers Meles meles track them? Wildlife Biology 15:197-206.

Machtans, C. S., M.-A. Villard, and S. J. Hannon. 1996. Use of riparian buffer strips as movement corridors by forest birds. Conservation Biology 10:1366-1379.

MacKenzie, D. I., J. D. Nichols, G. B. Lachman, S. Droege, J. A. Royle, And C. A. LANGtimm. 2003a. Estimating site occupancy rates when detection probabilities are less that one. Ecology 83:2248-2255.

MacKenzie, D. I., J. D. Nichols, J. A. Royle, K. H. Pollock, L. L. Bailey, and J. E. Hines. 2003b. Occupancy estimation and modeling. Academic Press, London, United Kingdom.

Maiorano, L., A. Falcucci, and L. Boitani. 2006. Gap analysis of terrestrial vertebrates in Italy: priorities for conservation planning in a human dominated landscape. Biological Conservation 133:455-473.

Malanson, G. P. 1993. Riparian landscapes. Cambridge University Press, Cambridge, United Kingdom.

Mangas, J. G., J. Lozano, S. Cabezas-Diaz, and E. Virgós. 2008. The priority value of scrubland habitats for carnivore conservation in Mediterranean ecosystems. Biodiversity and Conservation 17:43-51.

Matos, H. M., M. J. Santos, F. Palomares, and M. Santos-Reis. 2008. Does riparian habitat condition influence mammalian carnivore abundance in Mediterranean ecosystems? Biodiversity and Conservation 18:373-386.

Mortelliti, A., And L. Boitani. 2008. Interaction of food resources and landscape structure in determining the probability of patch use by carnivores in fragmented landscapes. Landscape Ecology 23:285-298.

Nagy, K. A., I. A. Girard, and T. K. Brown. 1999. Energetics of free-ranging mammals, reptiles, and birds. Annual Review of Nutrition 19:247-277.

Naiman, R. J., AND H. DÉcamps. 1997. The ecology of interfaces: riparian zones. Annual Review of Ecology and Systematics 28:621-658.

Palomares, F., AND M. Delibes. 1992. Circadian activity patterns of free-ranging large gray mongooses, Herpestes ichneumon, in southwestern Spain. Journal of Mammalogy 73:173-177.

Palomares, F., and M. Delibes. 1993. Key habitats for Egyptian mongooses in Doñana National Park, south-western Spain. Journal of Applied Ecology 30:752-758.

Perault, D. R., and M. V. Lomolino. 2000. Corridors and mammal community structure across a fragmented, old-growth forest landscape. Ecological Monographs 70:401-422.

Pereboom, V., M. Mergey, N. Villerette, R. Helder, J.-F. Gerard, AND T. LodE. 2008. Movement patterns, habitat selection, and corridor use of a typical woodland-dweller species, the European pine marten (Martes martes), in fragmented landscape. Canadian Journal of Zoology 86:983-991.
Pereira, M., ANd A. Rodriguez. 2010. Conservation value of linear woody remnants for two forest carnivores in a Mediterranean agricultural landscape. Journal of Applied Ecology 47:611-620.

Pires, A. E., And M. L. Fernandes. 2003. Last lynxes in Portugal? Molecular approaches in a pre-extinction scenario. Conservation Genetics 4:525-532.

Ray, J. C., And M. E. Sunquist. 2001. Trophic relations in a community of African rainforest carnivores. Oecologia 127:395408.

Ries, L., And W. F. Fagan. 2003. Habitat edges as a potential ecological trap for an insect predator. Ecological Entomology 28:567-572.

Rosalino, L. M., F. Loureiro, D. W. Macdonald, and M. SantosReIs. 2005a. Dietary shifts of the badger (Meles meles) in Mediterranean woodlands: an opportunistic forager with seasonal specialisms. Mammalian Biology 70:12-23.

Rosalino, L. M., D. W. MacDonald, and M. Santos-Reis. 2005b. Resource dispersion and badger population density in Mediterranean woodlands: is food, water or geology the limiting factor? Oikos 110:441-452.

Rosalino, L. M., and M. Santos-Reis. 2002. Feeding habits of the common genet Genetta genetta (Carnivora: Viverridae) in a seminatural landscape of central Portugal. Mammalia 66:195-205.

Rosalino, L. M., and M. Santos-Reis. 2008. Fruit consumption by carnivores in Mediterranean Europe. Mammal Review 39:67-78.

SABo, J. L., ET AL. 2005. Riparian zones increase regional species richness by harbouring different, not more, species. Ecology Letters 86:56-62.

Sadlier, L. M. J., C. C. Webbon, P. J. Baker, and S. Harris. 2004. Methods of monitoring red foxes Vulpes vulpes and badgers Meles meles: are field signs the answer? Mammal Review 34:75-98.

Salinas, M. J., G. Blanca, and A. T. Romero. 2000. Evaluating riparian vegetation in semi-arid Mediterranean watercourses in the south-eastern Iberian Peninsula. Environmental Conservation 27:24-35.

Santos, F. D., K. Forbes, and R. Moita. 2002. Climate change in Portugal. Scenarios, impacts and adaptation measures. Gradiva, Lisboa, Portugal.

Santos, M. J. 2010. Encroachment of upland Mediterranean plant species in riparian ecosystems of southern Portugal. Biodiversity and Conservation 19:2667-2684.

SAntos, M. J., AND P. Beier. 2008. Habitat selection by European badgers at multiple spatial scales in Portuguese Mediterranean ecosystems. Wildlife Research 35:835-843.

Santos, M. J., et AL. 2008. Assessing dam implementation impact on threatened carnivores: the case of Alqueva in SE Portugal. Environmental Monitoring and Assessment 142:47-64.

Santos, M. J., B. M. Pinto, and M. Santos-Reis. 2007. Is trophic niche partitioning the solution for the coexistence of carnivores in a Mediterranean landscape of SW Portugal? WebEcology 7:53-62.

SAntos-Reis, M. 1989. As doninhas ibéricas (Carnivora: Mustela) um estudo taxonómico e ecológico. Ph.D. dissertation, Universidade de Lisboa, Lisboa, Portugal.

Santos-Reis, M., M. J. Santos, S. Lourenco, J. T. Marques, I. Pereira, and B. Pinto. 2004. Relationships between stone martens, genets and cork oak woodlands in Portugal. Pp. 147-172 in Martens and fishers (Martes) in human-altered environments: an international perspective (D. J. Harrison, A. K. Fuller, and G. Proulx, eds.). Springer Academic, New York.

Sarmento, P. 1996. Feeding ecology of the European wildcat Felis silvestris in Portugal. Acta Theriologica 41:409-414. 
Scarascia-Mugnozza, G., H. Oswald, P. Piussi, and K. Radoglou. 2000. Forests of the Mediterranean region: gaps in knowledge and research needs. Forest Ecology and Management 132: 97-109.

Schmitz, O. J., P. A. Намвack, and A. P. Beckerman. 2000. Trophic cascades in terrestrial systems: a review of the effects of carnivore removals on plants. American Naturalist 155:141-153.

Schonewald-Cox, C., R. Azari, and S. Blume. 1998. Scale, variable density and conservation planning for mammalian carnivores. Conservation Biology 5:491-495.

Singleton, P. H., W. L. Gaines, And J. F. Lehmkuhl. 2002. Landscape permeability for large carnivores in Washington: a geographic information system weighted-distance and least-cost corridor assessment. United States Department of Agriculture Forest Service Pacific Northwest Research Station, Research Paper PNW-RP-549:1-89.

Smith, D. A., et AL. 2003. Detection and accuracy rates of dogs trained to find scats of San Joaquin kit foxes (Vulpes macrotis mutica). Animal Conservation 6:339-346.

Sunquist, M., And F. Sunquist. 2001. Changing landscapes: consequences for carnivores. Pp. 399-418 in Carnivore conservation (J. L. Gittleman, ed.). Cambridge University Press, Cambridge, United Kingdom.
Swihart, R. K., Z. Feng, N. A. Slade, D. M. Mason, and T. M. GeHring. 2001. Effects of habitat destruction and resource supplementation in a predator-prey metapopulation model. Journal of Theoretical Biology 210: 287-303.

Tablado, Z., J. L. Tella, J. A. Sanchez-Zapata, and F. Hiraldo. 2010. The paradox of long-term positive effects of a North American crayfish on a European community of predators. Conservation Biology 24:1230-1238.

VIRGós, E. 2001a. Relative value of riparian woodlands in landscapes with different forest cover for medium-sized Iberian carnivores. Biodiversity and Conservation 10:1039-1049.

Virgós, E. 2001b. Role of isolation and habitat quality in shaping species abundance: a test with badgers (Meles meles L.) in a gradient of forest fragmentation. Journal of Biogeography 28:381-389.

Williams, P., ET AL. 2003. Comparative biodiversity of rivers, streams, ditches and ponds in an agricultural landscape in southern England. Biological Conservation 115:329-341.

Zoran, D. L. 2002. The carnivore connection to nutrition in cats. Journal of the American Veterinary Medical Association 221:1559-1567.

Submitted 9 January 2010. Accepted 4 April 2011.

Associate Editor was Samantha Wisely. 